\title{
Single Agent Therapy
}

National Cancer Institute

\section{Source}

National Cancer Institute. Single Agent Therapy. NCI Thesaurus. Code C157514.

Pharmacotherapy consisting of a single agent. 